Sharif University of Technology
Scientia Iranica
Transactions C: Chemistry and Chemical Engineering
w w IEN.scientiairanica.com

\title{
Structural and electronic properties of alumaphosphinine complexes with metal ions: A theoretical study
}

\author{
H.R. Ghenaatian* \\ Department of Physics, Jahrom University, Jahrom, P.O. Box 74135-111, Iran. \\ Received 9 June 2015; received in revised form 3 December 2016; accepted 7 January 2017
}

\author{
KEYWORDS \\ Alumaphosphinine; \\ Metal ion; \\ Cation- $\pi$ interaction; \\ Atoms In Molecules \\ (AIM); \\ NICS; \\ Natural Bond Orbital \\ (NBO).
}

\begin{abstract}
Several complexes of alumaphosphinine ring with cations $\left(\mathrm{Li}^{+}, \mathrm{Na}^{+}, \mathrm{K}^{+}\right.$, $\mathrm{Be}^{2+}, \mathrm{Mg}^{2+}$, and $\mathrm{Ca}^{2+}$ ) were optimized at B3LYP/6-311++G(d,p), and the single-point calculations were performed at MP2/6-311++G(d,p) level of theory. Different aspects of cation- $\pi$ interaction, including interaction energy calculations, charge transfer values, and the variations in aromaticity of the ring upon complexation, were also considered. Natural Bond Orbital (NBO) analysis was performed to calculate the charge transfer and natural population analysis of the complexes. Quantum Theory of Atoms In Molecules (QTAIM) was also applied to analyze the properties of the bond critical points in the complexes. Finally, Nucleus Independent Chemical Shift (NICS), the Harmonic Oscillator Model of Aromaticity (HOMA), the Para-Delocalization Index (PDI), and the aromatic fluctuation index (FLU) were applied to evaluate the variation of aromaticity of the alumaphosphinine ring induced upon complexation.
\end{abstract}

(C) 2017 Sharif University of Technology. All rights reserved.

\section{Introduction}

The aromaticity and reactivity of isoelectronic heterocycles with benzene have attracted much interest for decades [1]. Replacement of carbon atoms in benzene by their analogs provides a series of compounds that are isoelectronic heterocycles with benzene. For example, replacement of carbon atoms by boron and nitrogen, boron and phosphorus, aluminum and nitrogen, aluminum and phosphorus produces borazine, boraphosphinine, alumazine, and alumaphosphinine compounds, respectively. These compounds have different chemical properties from those of benzene [2]. Theoretical studies have shown that six $\pi$ electrons are significantly localized on nitrogen and phosphorus atoms due to the large electronegativity differences between boron, aluminum, nitrogen, and phosphorus

\footnotetext{
*. Tel.: +9871 54372252; Fax: +98 71 54372254.

E-mail address: Ghenaat@jahrom.ac.ir
}

atoms. Due to the considerable electronegativity difference, the ring delocalization of electrons in the borazine, boraphosphinine, alumazine, and alumaphosphinine rings is weakened greatly [3]. Many theoretical considerations have been performed on the interaction of benzene ring with metal cations, although there are fewer considerations on the chemical properties of benzene analogs (borazine [4,5], boraphosphinine, alumazine, and alumaphosphinine rings).

For example, the binding affinity of alkali and alkaline metal cations with benzene and substituted benzene derivatives has been investigated in some studies $[4,6,7]$. Srinivas Reddy et al. also considered hydrated metal ion(s) $\left(\mathrm{Li}^{+}, \mathrm{Na}^{+}, \mathrm{K}^{+}, \mathrm{Mg}^{2+}\right.$, and $\mathrm{Ca}^{2+}$ ) complexes with benzene (cation- $\pi$ ) as model systems to perform quantum mechanical calculations in evaluating the geometrical parameters and interaction energies of these complexes [8]. Miao et al. [3] systematically investigated cation- $\pi$ and anion- $\pi$ interactions in complexes of borazine and B-trifluoroborazine with 
$\mathrm{Li}^{+}, \mathrm{Na}^{+}$, and $\mathrm{K}^{+}$cations and $\mathrm{F}^{-}, \mathrm{Cl}^{-}$, and $\mathrm{Br}^{-}$ anions. Their results showed that borazine and Btrifluoroborazine are able to form cation- $\pi$ and anion- $\pi$ complexes with the cations and anions. Kesherwani et al. [9] also investigated the binding affinity of borazine with different halides and oxyanions $\left(\mathrm{F}^{-}, \mathrm{Cl}^{-}, \mathrm{Br}^{-}\right.$, $\mathrm{HCOO}^{-}, \mathrm{CH}_{3} \mathrm{COO}^{-}, \mathrm{SO}_{4}^{2-}$, and $\mathrm{NO}_{3}^{-}$ions). Their results showed that the borazine has the most binding affinity with $\mathrm{F}^{-}$anion with respect to other anions, and it can be used as a sensor for fluoride ion.

Figure 1 shows delocalization of six valence electrons (one electronic pair on each atom) over six porbitals in alumaphosphinine ring. The electronegativities of $\mathrm{Al}$ and $\mathrm{P}$ atoms according to pauling are 1.61 and 2.19, respectively [10]. Thus, the difference of the electronegativities of $\mathrm{Al}$ and $\mathrm{P}$ atoms is $\Delta_{\mathrm{EN}}(\mathrm{P}-$ $\mathrm{Al})=0.58$, which should result in a decrease of aromatic stabilization of alumaphosphinine as compared to benzene $\left(\Delta_{\mathrm{EN}}(\mathrm{C}-\mathrm{C})=0\right)$. In this work, we studied cation- $\pi$ interaction between alumaphosphinine ring and $\mathrm{Li}^{+}, \mathrm{Na}^{+}, \mathrm{K}^{+}, \mathrm{Be}^{2+}, \mathrm{Mg}^{2+}$, and $\mathrm{Ca}^{2+}$ cations and the effects of metal complexation on the aromaticity of alumaphosphinine ring. QTAIM analysis was performed by AIM package to calculate the properties of Critical Points (CPs) [11]. In addition, the Natural Bond Orbital (NBO) analysis [12] was carried out to get more information about these complexes.

\section{Computational methods}

All of the initial structures of cation- $\pi$ complexes are designed with the cations $\left(\mathrm{Li}^{+}, \mathrm{Na}^{+}, \mathrm{K}^{+}, \mathrm{Be}^{2+}, \mathrm{Mg}^{2+}\right.$, and $\mathrm{Ca}^{2+}$ ) located on the normal lines of alumaphosphinine ring. These structures and metal ions are fully optimized at B3LYP/6-311++G(d,p) level of theory. Vibrational frequencies are calculated at the same level to ensure that each stationary point is a real minimum. After geometry optimization and frequency calculations, Zero-Point Energies (ZPEs) could be obtained. Then, single-point energy calculations are performed at the MP2/6-311++G(d,p) level of theory. The interaction energy for complexes of alumaphosphinine with metal ions is defined as follows: $\Delta E_{\text {int }}=E_{\text {(Complex })}-$ $E_{\text {(Alumaphosphinine) }}-E_{\text {(Metal ion) }}$. All interaction energies are corrected with Basis Set Superposition Errors (BSSE) using the Boys and Bernardi's counterpoise method [13]. All calculations are performed using the
Gaussian 98 program suit [14]. QTAIM analysis is also performed with AIM package [11] to calculate the properties of bond critical points (CCPs) in cation$\pi$ interaction. Also, the Natural Bonding Orbital (NBO) [12] is used to obtain the charge transfer values. On the other hand, the aromaticity of the alumaphosphinine ring and its complexes is measured using several well-established indices of aromaticity such as the Nucleus-Independent Chemical Shift (NICS) $[15,16]$, the Harmonic Oscillator Model of Aromaticity (HOMA) [17,18], the Para-Delocalization In$\operatorname{dex}(\mathrm{PDI})$ [19], the electron Localization-Delocalization Matrices (LDMs) [20,21], and the aromatic fluctuation index (FLU) [22] at B3LYP/6-311++G(d,p) level of theory using Multiwfn-3.2 program [23].

\section{Results and discussion}

\subsection{Optimized geometries of alumaphosphinine complexes}

In this study, we consider the complexes including alumaphosphinine ring and $\mathrm{Li}^{+}, \mathrm{Na}^{+}, \mathrm{K}^{+}, \mathrm{Be}^{2+}$, $\mathrm{Mg}^{2+}$, and $\mathrm{Ca}^{2+}$ metal ions. First, the metal cations are placed on the top of the alumaphosphinine ring, and the structures are optimized by B3LYP/6$311++\mathrm{G}(\mathrm{d}, \mathrm{p})$ level of theory. The optimized structures are shown in Figure 2. The distances between metal cations and the coordinating sites of alumaphosphinine ring in the complexes are also shown in Figure 2. It is seen that the distance of the ions to the phosphorus and aluminum atoms of alumaphosphinine ring increases with the increase of ion size from $\mathrm{Li}^{+}$to $\mathrm{K}^{+}$and from $\mathrm{Be}^{2+}$ to $\mathrm{Ca}^{2+}$ metal cations (see Figure 2).

To obtain accurate interaction energy values, single-point calculations (MP2/6-311++G(d,p) level) were performed on the optimized geometries. Then, the interaction energies were corrected by Zero-Point Energies (ZPEs) and basis set superposition error (Table 1). The structural properties of these complexes (Figure 2) confirm the expected trend of longer metalalumaphosphinine distances for heavier alkali $\left(\mathrm{Li}^{+}\right.$, $\mathrm{Na}^{+}$, and $\left.\mathrm{K}^{+}\right)$and alkaline earth $\left(\mathrm{Be}^{2+}, \mathrm{Mg}^{2+}\right.$, and $\mathrm{Ca}^{2+}$ ) metals. It can be seen that with the increase of ion size from $\mathrm{Li}^{+}$to $\mathrm{K}^{+}$and from $\mathrm{Be}^{2+}$ to $\mathrm{Ca}^{2+}$, the distance of the ions to the aluminum and phosphorus atoms of alumaphosphinine ring becomes greater. The interaction energies collected in Table 1 also show the

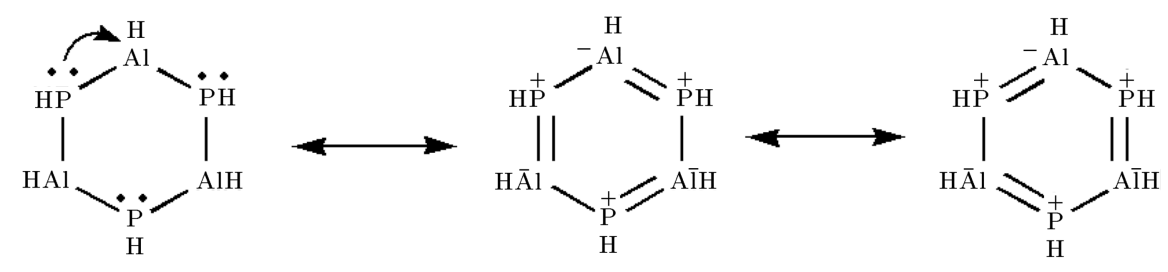

Figure 1. Delocalization in alumaphosphinine structure. 

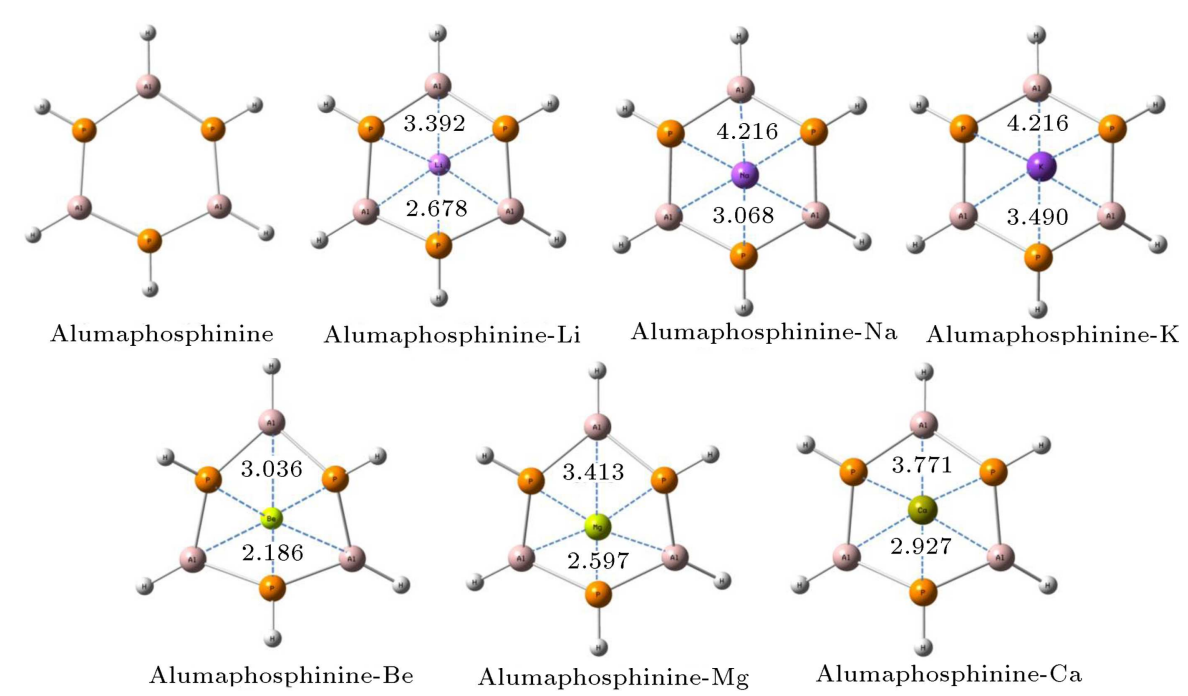

Figure 2. Optimized structures of the complexes formed by alumaphosphinine ring and $\mathrm{Li}^{+}, \mathrm{Na}^{+}, \mathrm{K}^{+}, \mathrm{Be}^{2+}, \mathrm{Mg}^{2+}$, and $\mathrm{Ca}^{2+}$ cations at B3LYP/6-311++G(d,p) level.

Table 1. Interaction energy ( $\mathrm{kcal} / \mathrm{mol})$ calculated for complexes of alumaphosphinine ring with $\mathrm{Li}^{+}, \mathrm{Na}^{+}, \mathrm{K}^{+}$, $\mathrm{Be}^{2+}, \mathrm{Mg}^{2+}$, and $\mathrm{Ca}^{2+}$ metal ions at

MP2/6-311++G(d,p)//B3LYP/6-311++G(d,p) level and the equilibrium distances from cation to the geometric center of the ring $\left(R_{e}, \AA\right)$.

\begin{tabular}{lcc}
\hline Structure & $\boldsymbol{\Delta} \boldsymbol{E}_{\text {int+BSSE }}$ & $\boldsymbol{R}_{\boldsymbol{e}}$ \\
\hline Alumaphosphinine-Li & -46.59 & 2.059 \\
Alumaphosphinine-Na & -35.94 & 2.349 \\
Alumaphosphinine-K & -27.65 & 2.651 \\
Alumaphosphinine-Be & -292.07 & 1.315 \\
Alumaphosphinine-Mg & 173.59 & 1.800 \\
Alumaphosphinine-Ca & 107.95 & 2.089 \\
\hline
\end{tabular}

expected trends. Table 1 shows that the values of interaction energy decrease with the increase of ion size from $\mathrm{Li}^{+}$to $\mathrm{K}^{+}$and from $\mathrm{Be}^{2+}$ to $\mathrm{Ca}^{2+}$. The decrease of interaction energy values is supposed by increasing cation equilibrium distance from the geometric center of the ring ( $R_{e}$ and $\AA$ ). The interaction energy values have the following order: alumaphosphinine$\mathrm{Li}>$ alumaphosphinine- $\mathrm{Na}>$ alumaphosphinine-K and alumaphosphinine-Be $>$ alumaphosphinine-Mg $>$ alumaphosphinine-Ca.

There is a correlation between the interaction energy values and the distance of $\mathrm{Li}^{+}, \mathrm{Na}^{+}, \mathrm{K}^{+}, \mathrm{Be}^{2+}$, $\mathrm{Mg}^{2+}$, and $\mathrm{Ca}^{2+}$ cations from centroid of alumaphosphinine ring (see Figure 3 ). It is seen that the values of interaction energy decrease with the increase of the distance of metal from centroid of alumaphosphinine ring. Exploring the complexes of alumaphosphinine ring shows that the alumaphosphinine ring has lost the planarity, more or less in the extent, upon the complexation with the cations. This "puckered structure"

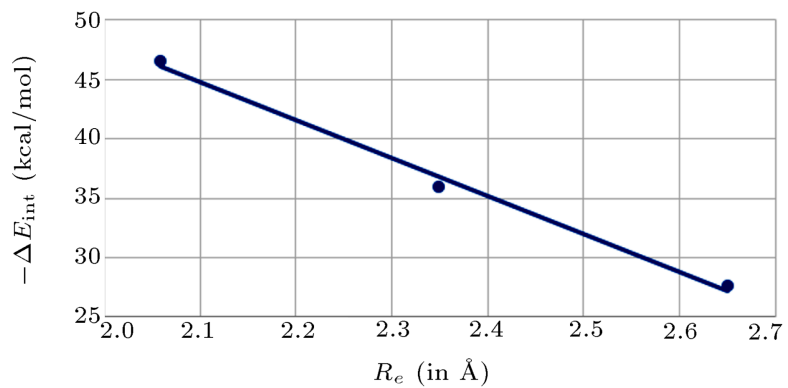

(a)

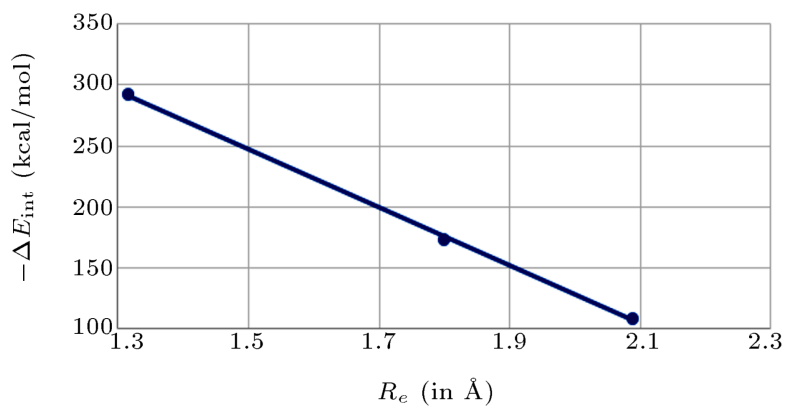

(b)

Figure 3. Correlations between the interaction energy values and the distance of $\mathrm{Li}^{+}, \mathrm{Na}^{+}, \mathrm{K}^{+}(3 \mathrm{a}), \mathrm{Be}^{2+}, \mathrm{Mg}^{2+}$ and $\mathrm{Ca}^{2+}(3 \mathrm{~b})$ cations from centroid of alumaphosphinine ring. The values of $R^{2}$ for these correlations are 0.991 and 0.999 , respectively.

is caused by attraction between cation and phosphorus and by repulsion between cation and aluminum; thus, three phosphorus atoms are dragged closer to the cation and three aluminum atoms pushed further away. As seen in Figure 2, the changes made in the complexes of $\mathrm{Be}^{2+}, \mathrm{Mg}^{2+}$, and $\mathrm{Ca}^{2+}$ are much more than those of $\mathrm{Li}^{+}, \mathrm{Na}^{+}$, and $\mathrm{K}^{+}$. This can be due to stronger interaction of alumaphosphinine ring with $\mathrm{Be}^{2+}, \mathrm{Mg}^{2+}$, and $\mathrm{Ca}^{2+}$ than that of other metal cations. The Al-P- 
Al-P dihedral angle in alumaphosphinine ring changes by the interaction of alumaphosphinine ring with $\mathrm{Li}^{+}$, $\mathrm{Na}^{+}, \mathrm{K}^{+}$and $\mathrm{Be}^{2+}, \mathrm{Mg}^{2+}$, and $\mathrm{Ca}^{2+}$ metal ions about $65.46^{\circ}, 66.57^{\circ}, 66.49^{\circ}, 66.03^{\circ}, 66.79^{\circ}$, and $69.76^{\circ}$, respectively. The results indicate that the changes in dihedral angles decrease with the increase of radius from $\mathrm{Li}^{+}$to $\mathrm{K}^{+}$and from $\mathrm{Be}^{2+}$ to $\mathrm{Ca}^{2+}$ cations.

\subsection{Quantum Theory of Atoms In Molecules (QTAIM) analysis}

According to the AIM theory [24], the presence of an interaction must correspond to the existence of a bond path between the donor and acceptor containing the BCP in topological analysis of the electron density distribution. Laplacian of $\rho(\mathbf{r})$ is related to the bond interaction energy by a local expression of the viral theorem:

$$
\frac{1}{2} \nabla^{2} \rho(\mathbf{r})=2 G(\mathbf{r})+V(\mathbf{r})
$$

where $G(\mathbf{r})$ is the electronic kinetic energy density, and $V(\mathbf{r})$ is the electronic potential energy density [24]. A negative $\nabla^{2} \rho(\mathbf{r})$ shows the excess potential energy at $\mathrm{BCP}$. It means that electronic charge is concentrated in the inter-nuclear region, and therefore, shared by two nuclei. This is the case in all shared electron (covalent) interactions. A positive $\nabla^{2} \rho(\mathbf{r})$ at a BCP reveals that the contribution of kinetic energy is greater than that of potential energy and shows depletion of electronic charge along the bond path. This is the case in all closed-shell electrostatic interactions [25]. The sign of $H(\mathbf{r})$ determines whether the accumulation of charge at a given point $(r)$ is stabilizing $(H(\mathbf{r})<0)$ or destabilizing $(H(\mathbf{r})>0)$. The energies for interaction of phosphorous atom and metal cation $\left(E_{\mathrm{P}} \ldots \mathrm{M}\right)$ are calculated by the following equation [26-29]:

$$
E_{\mathrm{P} \ldots \mathrm{M}}=1 / 2 V(\mathbf{r}) .
$$

Finally, the criterion nature of interaction between phosphorous atom and metal cation is evaluated by means of $-G(\mathbf{r}) / V(\mathbf{r})$ ratio. When $-G(\mathbf{r}) / V(\mathbf{r})>$ 1 , the interaction is noncovalent, while for $0.5<$ $-G(\mathbf{r}) / V(\mathbf{r})<1$, the interaction is partially covalent [30,31]. Results obtained for electron density topological properties at the Bond Critical Points (BCPs) of cation- $\pi$ interactions calculated at B3LYP $/ 6-311++\mathrm{G}$ $(\mathrm{d}, \mathrm{p})$ level are given in Table 2 .

Exploration of topological properties of complexes of alumaphosphinine with $\mathrm{Li}^{+}, \mathrm{Na}^{+}, \mathrm{K}^{+}$and $\mathrm{Be}^{2+}$, $\mathrm{Mg}^{2+}$, and $\mathrm{Ca}^{2+}$ metal ions revealed the presence of bond critical points connecting the cation with the phosphorous atoms. The laplacian of the bond critical points of $\mathrm{P} \cdots \mathrm{M}^{n+}$ is positive (see Table 2), indicating a depletion of the electron density, which is common in closed-shell interactions $[32,33]$. The ratio of $-G(\mathbf{r}) / V(\mathbf{r})$ for the bond critical points of $\mathrm{P} \cdots \mathrm{M}^{n+}$ also indicates that in the complexes of $\mathrm{Li}^{+}, \mathrm{Na}^{+}, \mathrm{K}^{+}$, $\mathrm{P} \cdot \mathrm{M}^{n+}$ interactions are noncovalent in the nature, while they are partially covalent in the complexes of $\mathrm{Be}^{2+}, \mathrm{Mg}^{2+}$, and $\mathrm{Ca}^{2+}$.

Table 2 shows that $\rho(\mathbf{r})$ values in the bond critical points of $\mathrm{P} \cdots \mathrm{M}^{n+}$ in the alumaphosphinine- $\mathrm{Be}^{2+}$, alumaphosphinine- $\mathrm{Mg}^{2+}$, and alumaphosphinine- $\mathrm{Ca}^{2+}$ complexes are more than those in alumaphosphinine$\mathrm{Li}^{+}$, alumaphosphinine- $\mathrm{Na}^{+}$, and alumaphosphinine-

\begin{tabular}{|c|c|c|c|c|c|c|c|c|c|}
\hline Structure & BCP & $\rho(\mathbf{r})$ & $\Delta \rho(\mathbf{r})$ & $\nabla^{2} \rho(\mathbf{r})$ & $G(\mathbf{r})$ & $V(\mathbf{r})$ & $H(\mathbf{r})$ & $-G(\mathbf{r}) / V(\mathbf{r})$ & $\begin{array}{c}E_{\mathrm{P}} \ldots \mathrm{M} \\
(\mathrm{kcal} / \mathrm{mol})\end{array}$ \\
\hline Alumaphosphinine & Al-P & 0.0663 & & 0.1491 & 0.0600 & -0.0828 & -0.0227 & 0.725 & - \\
\hline \multirow{2}{*}{ Alumaphosphinine-Li } & $\mathrm{P} \cdots \mathrm{Li}$ & 0.0121 & - & 0.0463 & 0.0104 & -0.0093 & 0.0011 & 1.12 & 2.92 \\
\hline & Al-P & 0.0635 & -0.0028 & 0.1158 & 0.0522 & -0.0753 & -0.0232 & 0.693 & - \\
\hline \multirow{2}{*}{ Alumaphosphinine-Na } & $\mathrm{P} \cdots \mathrm{Na}$ & 0.0093 & - & 0.0351 & 0.0075 & -0.0062 & 0.0013 & 1.21 & 1.94 \\
\hline & $\mathrm{Al} \cdots \mathrm{P}$ & 0.0638 & -0.0025 & 0.1135 & 0.0517 & -0.0750 & -0.0233 & 0.689 & - \\
\hline \multirow{2}{*}{ Alumaphosphinine-K } & $\mathrm{P} \cdots \mathrm{K}$ & 0.0074 & - & 0.0226 & 0.0046 & -0.0036 & 0.0010 & 1.27 & 1.13 \\
\hline & $\mathrm{Al} \cdots \mathrm{P}$ & 0.0639 & -0.0024 & 0.1130 & 0.0518 & -0.0754 & -0.0235 & 0.687 & - \\
\hline \multirow{2}{*}{ Alumaphosphinine-Be } & $\mathrm{P} \cdots \mathrm{Be}$ & 0.0555 & - & 0.0787 & 0.0422 & -0.0647 & -0.0225 & 0.65 & 20.30 \\
\hline & $\mathrm{Al} \cdots \mathrm{P}$ & 0.0585 & -0.0078 & 0.0885 & 0.0439 & -0.0656 & -0.0217 & 0.669 & - \\
\hline \multirow{2}{*}{ Alumaphosphinine-Mg } & $\mathrm{P} \cdots \mathrm{Mg}$ & 0.0295 & - & 0.0899 & 0.0244 & -0.0263 & -0.0019 & 0.93 & 8.25 \\
\hline & $\mathrm{Al} \cdots \mathrm{P}$ & 0.0596 & -0.0067 & 0.0947 & 0.0456 & -0.0676 & -0.0219 & 0.674 & - \\
\hline \multirow{2}{*}{ Alumaphosphinine-Ca } & $\mathrm{P} \cdots \mathrm{Ca}$ & 0.0263 & - & 0.0554 & 0.0156 & -0.0174 & -0.0018 & 0.900 & 5.46 \\
\hline & $\mathrm{Al} \cdots \mathrm{P}$ & 0.0607 & -0.0056 & 0.1012 & 0.0475 & -0.0698 & -0.0222 & 0.680 & - \\
\hline
\end{tabular}

Table 2. Selected electron density topological properties (in a.u.) in the complexes of alumaphosphinine ring. 


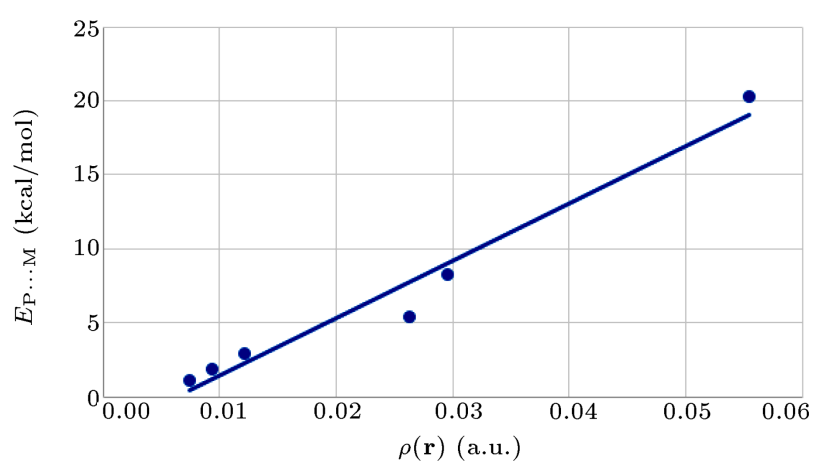

Figure 4. A correlation between $\rho(\mathbf{r})$ values in bond critical points of $\mathrm{P} \cdots \mathrm{M}^{n+}$ interaction and its energy $\left(E_{\mathrm{P}} \ldots \mathrm{M}\right)\left(R^{2}=0.965\right)$.

$\mathrm{K}^{+}$complexes. Thus, higher values of energy for $\mathrm{P} \cdots \mathrm{M}^{n+}$ interaction $\left(E_{\mathrm{P}} \ldots \mathrm{M}\right)$ are expected in these complexes. Figure 4 indicates the correlation between $\rho(\mathbf{r})$ values in bond critical points of $\mathrm{P} \cdots \mathrm{M}^{n+}$ interactions and their energies $\left(E_{\mathrm{P}} \cdots \mathrm{M}\right)$ in these complexes.

Another interesting feature studied in this section is the variation of the electron charge density in the bond critical points of Al-P bonds in the alumaphosphinine ring upon complexation of the ions. Because the electron density at the bond critical point provides a measure of the bond order, it can be reasonably assumed that the change in electron density at the bond critical point induced upon complexation gives a measure of the variation in the strength of the bond. The computed charge density values at the bond critical points of Al-P bonds in the ring and its variation upon complexation are presented in Table 2. Curiously, $\Delta \rho(\mathbf{r})$ values are negative for cation- $\pi$ complexes, indicating a reduction in the strength of Al-P bonds.

\subsection{Natural Population Analysis (NPA)}

The amount of Charge Transfer (CT) between alumaphosphinine ring and a cation is easily determined as the difference between the charge of the isolated cation and the atomic charge of the metal in the corresponding complexes. The smaller radius of the metal ion is, the more electron density can be transferred from the neutral ligand to the metal ion. Therefore, the transferred charge between alumaphosphinine ring and metal cations during complexation could be used as an indicator of the binding strength between the alumaphosphinine ring and the cations. Table 3 shows that the greatest charge transfers for alkali and alkaline earth metal cations occur in alumaphosphinine- $\mathrm{Li}^{+}$and alumaphosphinine$\mathrm{Be}^{2+}$ complexes, respectively, while the smallest charge transfer belongs to the alumaphosphinine- $\mathrm{K}^{+}$and alumaphosphinine- $\mathrm{Ca}^{2+}$ complexes, respectively. This result can be supported by less charge on $\mathrm{Li}^{+}$and $\mathrm{Be}^{2+}$ cations with respect to other metal cations in the complexes. Also, a positive charge on the cations in the complexes of $\mathrm{Li}^{+}, \mathrm{Na}^{+}, \mathrm{K}^{+}, \mathrm{Be}^{2+}$, $\mathrm{Mg}^{2+}$, and $\mathrm{Ca}^{2+}(0.905|\mathrm{e}|, 0.940|\mathrm{e}|, 0.972|\mathrm{e}|, 1.324|\mathrm{e}|$, $1.578|\mathrm{e}|$, and $1.738|\mathrm{e}|$, respectively) demonstrates that the alumaphosphinine ring transfers more amount of charge to $\mathrm{Li}^{+}$and $\mathrm{Be}^{2+}$ compared to other cations. Figure 4 shows that the more charge transfer values are, the higher interaction energy is expected. Thus, most of the charge transfers and interaction energy values are seen in alumaphosphinine-Be complex.

\subsection{Aromaticity of alumaphosphinine and its complexes}

The variation of the aromaticity of alumaphosphinine ring induced upon complexation is also considered by Nucleus-Independent Chemical Shift (NICS), the Harmonic Oscillator Model of Aromaticity (HOMA), the Para-Delocalization Index (PDI), and the aromatic fluctuation index (FLU) at B3LYP/6-311++G(d,p) level of theory.

Using the DFT optimized structures, NICS values were calculated using GIAO (gauge-independent atomic orbital) method [34]. NICS method is based on the negative values of the magnetic shielding computed at the centre of the ring. Significantly, negative values imply aromaticity (diatropic ring current), and positive values correspond to antiaromaticity (paratropic ring current). NICS at the geometrical center of the ring is influenced by the local (paratropic) effects arising mainly from $\sigma$ bonds. NICS(1.0) (1 $\AA$ above the plane

Table 3. The calculated NPA charges of the optimized structures of alumaphosphinine- $\mathrm{M}^{n+}\left(\mathrm{Li}^{+}, \mathrm{Na}^{+}, \mathrm{K}^{+}, \mathrm{Be}^{2+}, \mathrm{Mg}^{2+}\right.$, and $\mathrm{Ca}^{2+}$ ) complexes and the values of charge transfer.

\begin{tabular}{lcccccc}
\hline \multicolumn{1}{c}{ Structure } & QAl & QP & QAl-H & QP-H & QM & $\boldsymbol{\Delta q}_{\mathbf{C T}}$ \\
\hline Alumaphosphinine & 1.046 & -0.801 & -0.322 & 0.077 & - & - \\
Alumaphosphinine-Li & 1.097 & -0.873 & -0.296 & 0.103 & 0.905 & 0.095 \\
Alumaphosphinine-Na & 1.074 & -0.850 & -0.302 & 0.094 & 0.940 & 0.060 \\
alumaphosphinine-K & 1.052 & -0.819 & -0.307 & 0.083 & 0.972 & 0.028 \\
Alumaphosphinine-Be & 1.271 & -0.953 & -0.250 & 0.158 & 1.324 & 0.676 \\
Alumaphosphinine-Mg & 1.217 & -0.962 & -0.257 & 0.143 & 1.578 & 0.422 \\
Alumaphosphinine-Ca & 1.167 & -0.953 & -0.261 & 0.135 & 1.738 & 0.262 \\
\hline
\end{tabular}


Table 4. Different indices of aromaticity (NICS ( $\mathrm{ppm}$ ), HOMA, PDI (electrons), and FLU) for alumaphosphinine ring and its complexes, calculated at the B3LYP/6-311++G(d,p) level of theory.

\begin{tabular}{lccccccc}
\hline \multicolumn{1}{c}{ Structure } & NICS(0) & NICS(0.5) & NICS(1) & $\boldsymbol{\Delta N I C S ( 1 )}$ & HOMA & PDI & FLU \\
\hline Alumaphosphinine & -11.8687 & -10.1931 & -6.5036 & - & 1 & 0.022636 & 0.004236 \\
Alumaphosphinine-Li & -10.2060 & -8.5158 & -5.4209 & 1.0827 & 0.6435 & 0.020465 & 0.001139 \\
Alumaphosphinine-Na & -7.9520 & -7.8381 & -5.7480 & 0.7556 & 0.6086 & 0.01939 & 0.00206 \\
Alumaphosphinine-K & -6.3791 & -7.9296 & -6.0464 & 0.4572 & 0.6196 & 0.019864 & 0.00078 \\
Alumaphosphinine-Be & -11.66 & -8.0915 & -4.5209 & 1.9827 & -0.4329 & 0.023478 & 0.036212 \\
Alumaphosphinine-Mg & -7.1966 & -6.4702 & -4.2487 & 2.2549 & -0.2484 & 0.020864 & 0.030023 \\
Alumaphosphinine-Ca & 7.5926 & -7.6991 & -5.8306 & 0.673 & 0.0600 & 0.016872 & 0.015923 \\
\hline
\end{tabular}

of the ring) essentially reflects $\pi$ effects and is a better indicator of the ring current than the value at the center. The NICS values in the complexes are calculated below the centre of the ring, on the opposite face to the ion. Then, the variation of the aromaticity of the ring induced upon complexation is calculated $(\Delta \mathrm{NICS}$ $=$ NICS $($ complex) - NICS (isolated alumaphosphinine ring), see Table 4). Cation- $\pi$ complexes give a positive variation of the NICS, indicating a diminution in the aromaticity of the alumaphosphinine ring upon complexation of the cation. These results are in agreement with the variation of the electron density at the bond critical points of Al-P bonds in the ring upon binding of the ions.

The Harmonic-Oscillator Model of Aromaticity (HOMA) index is found to be among the most widespread and effective indices of aromaticity founded on structural criteria. As a structural criterion, the HOMA index $[17,18]$ was used, as shown in Eq. (3):

$$
\mathrm{HOMA}=1-\frac{\alpha}{n} \sum_{i}^{n}\left(R_{\mathrm{opt}, j}-R_{j, i}\right)^{2} .
$$

In this equation, $\alpha$ is an empirical constant (for Al$\mathrm{P}$ bond $\alpha=122.07$ ) chosen to give HOMA $=0$ for a nonaromatic system and HOMA $=1$ for system where all bonds are equal to an optimal bond length $\left(R_{o p t}\right.$, $2.266 \AA$ for Al-P bond), $n$ is the number of bonds taken into summation, $R_{i}$ is an individual bond length, and $j$ represents the type of the bond.

As seen from interaction energies in Table $1, \mathrm{Be}^{2+}$ and $\mathrm{Mg}^{2+}$ ions strongly interact with alumaphosphinine ring, and thus, the largest deviations of bond lengths from optimal values are seen in their complexes. However, the calculated HOMA index classifies alumaphosphinine-Be and alumaphosphinine-Mg complexes as anti-aromatic and alumaphosphinine-Ca complex as almost nonaromatic. In addition, the HOMA index indicates that the aromaticity of alumaphosphinine ring decreases upon adsorption of $\mathrm{Li}^{+}, \mathrm{Na}^{+}$, and $\mathrm{K}^{+}$ions in such a way that alumaphosphinine$\mathrm{Li}^{+}$has the highest interaction energy, thus the lowest aromaticity value than those of $\mathrm{Na}^{+}$and $\mathrm{K}^{+}$ions.

The para-delocalization (PDI) index was em- ployed as an electron delocalization index [19]. It is derived from Bader's Atoms In Molecules (AIM) theory [24,25,32] and represents the average of Delocalization Indices (DI) of para-related atoms in a given six-membered ring. The underlying idea of this index is that the delocalization of the electron density in benzene is greater between para-related carbons than between meta-related carbons [19]. The Delocalization Index (DI) measures the number of electrons delocalized between two atoms. The PDI value increases with increasing aromaticity of a ring. Calculation of PDI values indicates that the aromaticity value of alumaphosphinine ring decreases further with increasing interaction energy values from $\mathrm{K}^{+}$ to $\mathrm{Li}^{+}$ion, although a good correlation is not seen between interaction energy and aromaticity changes when $\mathrm{Be}^{2+}, \mathrm{Mg}^{2+}$, and $\mathrm{Ca}^{2+}$ ions interact with the alumaphosphinine ring. This may be due to strong interaction of these ions with alumaphosphinine ring, and thus, large deviation of ring from planar mode.

FLU is an aromaticity index based on DI. FLU not only analyzes the amount of electron sharing between adjacent atoms in a given ring, which should be substantial in aromatic molecules, but it also takes into account the similarity of electron sharing between adjacent atoms. This index measures weighted electron delocalization divergences with respect to typical aromatic molecules. FLU should give a number close to zero for any aromatic molecule. As seen from Table 4, FLU values for the alumaphosphinine$\mathrm{Be}$, alumaphosphinine- $\mathrm{Mg}$, and alumaphosphinine-Ca complexes are more away from zero than those for the alumaphosphinine-Li, alumaphosphinine- $\mathrm{Na}$, and alumaphosphinine-K complexes; thus, $\mathrm{Be}^{2+}, \mathrm{Mg}^{2+}$, and $\mathrm{Ca}^{2+}$-complexes are less aromatic than $\mathrm{Li}^{+}, \mathrm{Na}^{+}$, and $\mathrm{K}^{+}$-complexes.

\section{Conclusion}

The structure of alumaphosphinine- $\mathrm{M}^{n+}$ (where $\mathrm{M}^{n+}$ is $\mathrm{Li}^{+}, \mathrm{Na}^{+}, \mathrm{K}^{+}, \mathrm{Be}^{2+}, \mathrm{Mg}^{2+}$, and $\mathrm{Ca}^{2+}$ cations) complexes was optimized and studied by the density functional method using B3LYP functional and 6$311++\mathrm{G}(\mathrm{d}, \mathrm{p})$ basis set. The calculation of interaction 
energies shows that the values of interaction energy decrease with the increase of ion size from $\mathrm{Li}^{+}$to $\mathrm{K}^{+}$and from $\mathrm{Be}^{2+}$ to $\mathrm{Ca}^{2+}$. Therefore, $\mathrm{Li}^{+}$and $\mathrm{Be}^{2+}$ cations have the highest interaction energy values with respect to other metal cations. The results also indicate that the equilibrium distance from cation to the geometric center of the ring $\left(R_{e}\right)$ increases with the decrease of interaction energy values.

The results of NBO and AIM analyses can be summarized as follows: The results of QTAIM analysis indicate that in the complexes of $\mathrm{Li}^{+}, \mathrm{Na}^{+}$, and $\mathrm{K}^{+}$, $\mathrm{P} \cdots \mathrm{M}^{n+}$ interactions are noncovalent in the nature, while they are partially covalent in the complexes of $\mathrm{Be}^{2+}, \mathrm{Mg}^{2+}$, and $\mathrm{Ca}^{2+}$. Also, $\rho(\mathbf{r})$ values in the bond critical points of $\mathrm{P} \cdots \mathrm{M}^{n+}$ in alumaphosphinine- $\mathrm{Be}^{2+}$, alumaphosphinine- $\mathrm{Mg}^{2+}$, and alumaphosphinine- $\mathrm{Ca}^{2+}$ complexes are more than those in alumaphosphinine$\mathrm{Li}^{+}$, alumaphosphinine-Na ${ }^{+}$, and alumaphosphinine$\mathrm{K}^{+}$complexes. A reduction in the strength of the Al$\mathrm{P}$ bonds in the alumaphosphinine ring is created by cation- $\pi$ interaction.

The results of NBO also show that the values of charge transfer from alumaphosphinine ring to $\mathrm{Li}^{+}$ and $\mathrm{Be}^{2+}$ cations are higher than other cations. This result can be supported by less charge on $\mathrm{Li}^{+}$and $\mathrm{Be}^{2+}$ cations than other cations in the complexes. Calculation of aromaticity values with NICS method, HOMA, PDI, and FLU shows that a decrease of aromaticity is observed upon complexation. Finally, our study may be helpful to the further investigation of inorganic aromatic ring in the area of cation recognition or other relevant research areas.

\section{Acknowledgement}

The author gratefully acknowledges financial support from the Research Council of Jahrom University.

\section{References}

1. Daly, M.M., Tanjaroon, C., Marwitz, A.J.V., Liu, S.Y. and Kukolich, S.G. "Microwave spectrum, structural parameters, and quadrupole coupling for 1,2-dihydro1,2-azaborine", J. Am. Chem. Soc., 132, pp. 5501-5506 (2010).

2. Lisovenko, A.S. and Timoshkin, A.Y. "Theoretical study of donor-acceptor ability of borazine, alumazine, and boraphosphinine", Russ. J. Gen. Chem., 81, pp. 831-839 (2011).

3. Miao, R., Yang, G., Zhao, C., Hong, J. and Zhu, L. "Theoretical study of borazine and its fluoroderivatives: aromaticity and cation- $\pi$, anion- $\pi$ interaction", J. Mol. Struct. THEOCHEM, 715, pp. 91-100 (2005).

4. Bania, K.K., Guha, A.K., Bhattacharyya, P.K. and Sinha, S. "Effect of substituent and solvent on cation- $\pi$ interactions in benzene and borazine: A computational study", Dalton Trans., 43, pp. 1769-1784 (2014).
5. Zhuo, H., Li, Q., An, X., Li, W. and Cheng, J. "Influence of the nature of hydrogen halides and metal cations on the interaction types between borazine and hydrogen halides", J. Mol. Model., 20, pp. 2089-2096 (2014).

6. Khanmohammadi, A., Raissi, H., Mollania, F. and Hokmabadi, L. "Molecular structure and bonding character of mono and divalent metal cations $\left(\mathrm{Li}^{+}\right.$, $\mathrm{Na}^{+}, \mathrm{K}^{+}, \mathrm{Be}^{2+}, \mathrm{Mg}^{2+}$, and $\mathrm{Ca}^{2+}$ ) with substituted benzene derivatives: AIM, NBO, and NMR analyses", Struct. Chem., 25, pp. 1327-1342 (2014).

7. Dinadayalane, T.C., Afanasiev, D. and Leszczynski, J. "Structures and energetics of the cation- $\pi$ interactions of $\mathrm{Li}^{+}, \mathrm{Na}^{+}$, and $\mathrm{K}^{+}$with cup-shaped molecules: Effect of ring addition to benzene and cavity selectivity", J. Phys. Chem. A, 112, pp. 7916-7924 (2008).

8. Srinivas Reddy, A., Zipse, H. and Narahari Sastry, G. "Cation- $\pi$ interactions of bare and coordinatively saturated metal ions: Contrasting structural and energetic characteristics", J. Phys. Chem. B, 111, pp. 1154611553 (2007).

9. Kesharwani, M.K., Suresh, M., Das, A. and Ganguly, B. "Borazine as a sensor for fluoride ion: A computational and experimental study", Tetrahedron, 52, pp. 3636-3639 (2011).

10. Emsley, J., The Elements, Oxford: Clarendon Press (1991).

11. a) Biegler-König, F.W., SchÖnbohm, J. and Bayles, D. "AIM2000 - A program to analyze and visualize atoms in molecules", J. Comput. Chem., 22, pp. 545559 (2001);

b) Biegler-König, F.W. "Calculation of atomic integration data", J. Comput. Chem., 21, pp. 1040-1048 (2000);

c) Biegler-König, F.W., Schönbohm, J. and Bayles, D., AIM 2000 program can be downloaded from Internet at http://gauss.fh-bielefeld.de/aim2000. Web Page.

12. Reed, A.E., Curtiss, L.A. and Weinhold, F. "Intermolecular interactions from a natural bond orbital, donor-acceptor viewpoint", Chem. Rev., 88, pp. 899926 (1988).

13. Boys, S.F. and Bernardi, R. "The calculation of small molecular interactions by the differences of separate total energies. Some procedures with reduced errors", Mol. Phys., 19, pp. 553-566 (1979).

14. Frisch, M.J., Trucks, G.W., Schlegel, H.B., et al. Gaussian 98W, revision A.1, Gaussian, Pittsburgh.

15. Wolinski, K., Hilton, J.F. and Pulay, P. "Efficient implementation of the gauge-independent atomic orbital method for NMR chemical shift calculations", J. Am. Chem. Soc., 112, pp. 8251-8260 (1990).

16. Chen, Z., Wannere, C.S., Corminboeuf, C., Puchta, R. and Schleyer, PvR. "Nucleus-independent chemical shifts (NICS) as an aromaticity criterion", Chem. Rev., 105, pp. 3842-3888 (2005).

17. Krygowski, T.M. and Cyranski, M.K. "Separation of the energetic and geometric contributions to the 
aromaticity. Part IV. A general model for the $\pi$ electron systems", Tetrahedron, 52, pp. 10255-10264 (1996).

18. Andrzejak, M., Kubisiak, P. and Zborowski, K.K. "Avoiding pitfalls of a theoretical approach: the harmonic oscillator measure of aromaticity index from quantum chemistry calculations", Struct. Chem., 24, pp. 1171-1184 (2013).

19. Poater, J., Fradera, X., Duran, M. and Solà, M. "The delocalization index as an electronic aromaticity criterion: Application to a series of planar polycyclic aromatic hydrocarbons", Chem. Eur. J., 9, pp. 400406 (2003).

20. Sumar, I., Cook, R., Ayers, P.W. and Matta, C.F. "AIMLDM: A program to generate and analyze electron localization-delocalization matrices (LDMs)", Comput. Theor. Chem., 1070, pp. 55-67 (2015).

21. Sumar, I., Cook, R., Ayers, P.W. and Matta, C.F. "Aromaticity of rings-in-molecules (RIMs) from electron localization-delocalization matrices (LDMs)", Phys. Scr., 91, pp. 013001-013013 (2016).

22. Matito, E., Duran, M. and Solà, M. "The aromatic fluctuation index (FLU): A new aromaticity index based on electron delocalization", J. Chem. Phys., 125, p. 59901 (2005).

23. Lu, T. and Chen, F. "Multiwfn: a multifunctional wavefunction analyzer", J. Comp. Chem., 33, pp. 580592 (2012).

24. Bader, R.F.W. "A bond path: A universal indicator of bonded interactions", J. Phys. Chem. A, 102, pp. 7314-7323 (1998).

25. Bader, R.F.W., Atoms in Molecules: A Quantum Theory, New York, Oxford University Press (1990).

26. Shakourian-Fard, M., Kamath, G. and Jamshidi, Z. "Trends in physisorption of ionic liquids on boronnitride sheet", J. Phys. Chem. C, 118, pp. 26003-26016 (2014).

27. Shakourian-Fard, M. and Fattahi, A. "Theoretical investigation on the structural and electronic properties of complexes formed by thymine and $2^{\prime}-$ deoxythymidine with different anions", Struct. Chem., 23, pp. 17-28 (2011).
28. Aliakbar Tehrani, Z., Abedin, A., Shakourian-Fard, M. and Fattahi, A. "What roles do boron substitutions play in structural, tautomeric, base pairing and electronic properties of uracil? NBO \& AIM analysis", $J$. Phys. Org. Chem., 25, pp. 787-796 (2012).

29. Shakourian-Fard, Jamshidi, Z., Bayat, A. and Kamath, G. "Meta-hybrid density functional theory study of adsorption of imidazolium and ammoniumbased ionic liquids on graphene sheet", J. Phys. Chem. C, 119, pp. 7095-7108 (2015).

30. Abboud, J.L.M., Mó, O., De Paz, J.L.G., et al. "Thiocarbonyl versus carbonyl compounds: A comparison of intrinsic reactivities", J. Am. Chem. Soc., 115, pp. 12468-12476 (1993).

31. Rozas, I., Alkorta, I. and Elguero, J. "Behavior of ylides containing $\mathrm{N}, \mathrm{O}$, and $\mathrm{C}$ atoms as hydrogen bond acceptors", J. Am. Chem. Soc., 122, pp. 11154-11161 (2000).

32. Bader, R.F.W. "A quantum theory of molecular structure and its applications", Chem. Rev., 91, pp. 893-928 (1991).

33. Shakourian-Fard, M., Fattahi, A. and Bayat, A. "Ionic liquid based on $\alpha$-amino acid anion and N7,N9dimethylguaninium cation ([dMG][AA]): Theoretical study on the structure and electronic properties", $J$. Phys. Chem. A, 116, pp. 5436-5444 (2012).

34. Wolinski, K., Hilton, J.F. and Pulay, P. "Efficient implementation of the gauge-independent atomic orbital method for NMR chemical shift calculations", J. Am. Chem. Soc., 112, pp. 8251-8260 (1990).

\section{Biography}

Hamid Reza Ghenaatian was born in Jahrom, Fars province, Iran. He received his BSc in Pure Chemistry from Ferdowsi University of Mashhad and his MSc and $\mathrm{PhD}$ degrees from Tarbiat Modares University of Tehran under supervision of Professor Mir Fazlollah Mousavi. He is currently an academic staff and dean of the Faculty of Sciences in Jahrom University, Jahrom, Iran. His research interests include theoretical and applicable chemistry fields of nanomaterials; he has published many books and papers in these fields. 